\section{A Midwife through the Dying Process: Stories of Healing and Hard Choices at the End of Life}

T E Quill, Baltimore, Johns Hopkins University Press, 1996, 239 pages, $£ 20$.

This is a book about the humaneness of modern medical care at the end of life, at once deeply moving and disturbing, comforting and challenging. The author is a doctor who is no stranger to controversy. His passionate belief that doctors have a responsibility to commit themselves to responding appropriately and sympathetically to their dying patients has led him through the courts as well as to the Netherlands. He writes with conviction and courage.

Defining medicine's purpose solely as one of curing and prolonging life can limit the way death is perceived. Dying is no longer a natural and inevitable part of life but rather a medical failure to be resisted at all costs. As a consequence of such an approach, many patients pass from life to death enduring the indignity and violence of chest compression, electric shocks, insertion of tubes and the sounds of staccato orders. This book is about those cases where the extension of biological life is not what the patient wants. It does not shy away from that approximately five per cent of terminally ill patients for whom conventional medicine has no means of treating their agony and intolerable disintegration. It is about enhancing the quality and meaning of such lives and deaths.

A vast literature exists on the ethics of life and death decision-making. This volume is different. It contains none of the familiar philosophical jargon but, remaining rooted in clinical reality, it exposes the potential for self-deception in some of the paper-thin distinctions often made between passive and active measures, and legal and illegal acts. Despite the complexity of decisionmaking, despite the legal, ethical and clinical uncertainties, patients, families and doctors are struggling with these questions every day - not because they want to, but because they have to. Ethicists and lawyers may well assert that there is no significant distinction to be drawn between stopping and starting life-supporting therapy. For the clinician they can be emotionally very distinct, as this book vividly shows. Even what is theoretically passive can feel active. Even when a therapy is discontinued on the express instructions of the patient the medical responsibility can feel burdensome. Quill meets these challenges head on: what should doctors do when patients refuse life-sustaining treatment? What should they do faced with requests from patients to put an end to their suffering? Is it acceptable to have patients forced to die with a plastic bag over their heads? When does compassion override legal imperative? What about incurably ill, suffering people who are not imminently dying?

But he also recognises there are limits, capturing eloquently the agony of being torn between a duty to help and a need to protect oneself. His is not a reckless disregard for medical convention or the law. Rather he argues for the creation of "an atmosphere in which it is not only legally safe but also professionally and morally mandatory" for doctors to provide a way through the suffering of incurable illness and death.

Our society tends to make rigid distinctions between the methods employed to ease a patient's death that bear little relation to the degree of suffering involved. Dr Quill's contention is that the method used at the very end of life is relatively unimportant provided it is consistent with the values of the patient and doctor con- cerned. It is the process of mutuag decision-making, caring and compas sion over time that is much more central to the care of the dying that the final act. He leaves behind the security of ivory tower theorising, an\& recounts the stories of nine of his patients who directly faced challenges and choices about dying, and whose cases challenge medical thinking. IF exploring nine very different scenariog he emphasises the uniqueness of eact patient, each set of circumstance and illustrates the reality that there is not just one major choice to be mades but a series of steps of varying ngige nitude. He underlines both the resilience of the human spirit andōhe unexpectedness of human reactions Moments of truth and stark choice present with unanticipated suddena ness. Constant readjustments aro necessary. These are made with vary ing degrees of success. "Walking th walk" with the dying patient is not easy, but again and again the message emerges that intolerable suffering is what the patient says it is, and canno be measured on the observer $\$$ barometer.

Helping people to die well is both $\frac{3}{3}$. privilege and a burden. The pain of inadequate solutions to intractable situations can be acute. "Forcing patients and doctors to let nature taks its course under these harsh circun? stances, especially after having previ ously intervened so aggressively and 'unnaturally', is morally unaccepto able," Quill argues, "Our obligatio성 not to abandon requires that we search for and find acceptable solve tions." In setting out to stimulate reflection and introspection, ho encourages any willing reader to worf towards his or her own solutionso Though his arguments are by nō means exhaustive he neverthele $\overrightarrow{8}$ offers a useful set of references of each issue to encourage more detaile exploration. There is an element \& repetition in places, but the wisdom behind this work and the challenge to 
professionals to match their technological advances with a heightened sensitivity to the humaneness of terminal care make this a valuable book for anyone who cares about the manner of a person's dying.

\section{HAZEL E MCHAFFIE Medical Ethics, Department of Medicine, University of Edinburgh}

\section{Genetic Intervention in Human Subjects}

\author{
The Report of a Working Party of the \\ Catholic Bishops' Joint Committee \\ on Bioethical Issues, London, The \\ Catholic Bishop's Joint Committee \\ on Bioethical Issues, 1996, 80 pages, \\ $£ 6.95$.
}

The Catholic Bishops' Joint Committee on Bioethical Issues has worked hard and earnestly at discussing the possibilities and problems which could arise from the application of genetic engineering and related techniques in the areas of human potential, health and welfare.

This booklet falls into two main sections; the genetic and the ethical. The committee sought medical and scientific advice, and their outline of genetics, cell biology, recombinant technology, and gene therapy for particular conditions is simple but succinct, and they have provided a glossary. There are two appendices, one on the legal questions which might arise from genetic intervention and one of extracts from Vatican documents.

It is the section on ethics which is the core concern of the book, and this rests in part on the advice the bishops received on technical and medical matters, but most importantly on the basic assumptions derived from their beliefs and philosophy.

There are two major premises which determine their conclusions, so it is important to examine these premises in order to understand their arguments. Their first premise is that: "On current evidence the human whole appears to originate at fertilisation" (page 17), and therefore that: ". . . not only the infant but the fetus and embryo have morally significant interests . . ." (page 18). Inferring that the zygote at the moment of fertilisation is morally equivalent to an infant, and should be accorded the same respect and value leads to the conclusion that in vitro fertilisation, prenatal screening, and abortion at any stage are all equally ethically objectionable, because they involve selection and therefore rejection of those not chosen: any manipulation is an act of domination and treats the child as a commodity. The bishops do not appear to know that a high proportion of human zygotes are normally spontaneously lost, and that the majority of these losses are probably genetically and developmentally grossly abnormal. A significant proportion of "late" menstruations in sexually active unprotected women may actually contain a rejected early conceptus. Nor do the bishops consider the possibility that human biochemistry is not the same as human personhood: you can't have a human without a human genome, which holds the potential for a person, but this has to become actual through the processes of differentiation and development; so that it does not inevitably imply a person. An anencephalic has human DNA but few, if any, would regard it or cherish it as a person. It should never be attempted, but if, hypothetically, a human were to be derived from somatic cell DNA, as Dolly the sheep was recently derived, would this origin negate the humanity?

They do not accept that the relationship between genome and personhood lies on a continuum from a potential to a person during development, yet they effectively admit to a continuum in the relationship between the individual and the amount of the genome which may be modified. The uniqueness of a person is not tied to the individual's genome (page 32), but "thoughtless manipulation" of gametes or embryos could transform speciesspecific sequences and alter "the spiritual and physical integrity" of the individual (page 55).

I agree with them that we are all imperfect, and that state support for the disabled is a moral requirement. However, screening to prevent the development of a severely disabled fetus, whether for genetic or developmental reasons, is not incompatible with cherishing and caring for a disabled child from birth onwards, although it is established that couples with a disabled child are statistically more likely to break up and that other, healthy, children of the marriage may become damaged by feeling neglected and unimportant. The bishops recommend that genetic counsellors should "be obliged to work with disabled children ... outside of the clinical context" (how - as the parent of a disabled child?), and that they should be "trained in advocacy for the disabled" (page 27). This might be thought by some, including myself, to be different from counselling as it is generally understood, and to have an element in it of the domination of parents who are anxious and vulnerable, because it is the parents, not the counsellor who will be responsible, and probably unsupported, in the years to come.

Their second premise is that the only morally acceptable way to produce a zygote is by the unimpeded and unprotected intromission of a penis into a vagina. This would seem to make loving sex and rape both morally superior to in vitro fertilisation. An act of rape is an act of domination and uses the woman as a commodity, yet it is in vitro fertilisation which troubles the bishops: they write that it treats a child as a commodity, and is, therefore, domination; yet infertile couples may turn to it in hope and longing and greatly cherish the child so conceived.

Throughout the bishops are concerned that any manipulation which is therapeutic in intent must not involve screening embryos nor require anything other than normal intercourse, which can be assisted but not prevented or replaced. To do otherwise fails to accord dignity to all involved. They approve genetic therapy to restore reproductive potential, for individuals with genetic diseases (including treatment of the very early embryo with replacement in the fallopian tube), and would accept screening and subsequent genetic therapy of gametes or their precursors. For example, unfertilised ova, they suggest, could be treated and then be replaced in the fallopian tube ready to meet sperm as a result of "normal intercourse" which, they say, would be "safer and simpler than alternatives" (page 43). Unless the mother is treated by hormones, one would expect only one ovum at a time. How would unfertilised ova be screened? Surgery would be required to access the ovum and then to replace it in the fallopian tube, and normal intercourse should not be delayed. The bishops are concerned to respect the dignity of the conceptus and the human and penile dignity of the husband, who, one hopes will remember to say "That 